\title{
DESAIN SARANA BAWA PERALATAN DAN WORKSTATION PEMBERSIH SEPATU SNEAKER
}

\author{
SHIDDIQ ARIFIN DWI PUTRA \\ Mahasiswa Program Studi Desain Produk, Jurusan Desain \\ Politeknik Negeri Samarinda \\ Roni H \\ Staf Pengajar Program Studi Desain Produk, Jurusan Desain \\ Politeknik Negeri Samarinda \\ Email: iron_082@yahoo.co.id
}

\begin{abstract}
ABSTRAK
Peralatan atau perkakas pembersih sepatu pada umumnya menggunakan box atau kotak yang menggunakan material kayu maupun plastik kaca sehingga akan memiliki jangka waktu penyimpanan yang tidak cukup panjang. Tetapi, sarana pembawa peralatan pembersih sepatu yang ada saat ini hanya diperuntukan untuk pengguna sepatu berbahan kulit. Sehingga, memiliki keterbatasan untuk pengguna sepatu sneaker yang berbahan kanvas, nylon, suede, dan kulit sintetis. Untuk perawatannya sendiri masih menggunakan metode dry cleaning untuk jenis sepatu sneaker berbahan suede. Tetapi belum menerapkan metode pembersihan wet cleaning untuk sepatu sneaker yang berbahan kanvas, nylon, dan kulit sintetis. Oleh karena itu, perancang berencana membuat sarana membawa peralatan pembersih sepatu sneaker yang disertai meja alas pembersih sepatu sneaker dengan metode dry cleaning dan wet cleaning. Dalam laporan ini yang berjudul "Desain Sarana Bawa Peralatan dan Workstation Pembersih Sepatu Sneaker" memberi alternatif baru dalam desain sarana bawa khususnya pembersih sepatu sneaker. Metode perancangan yang dilakukan yaitu melakukan preliminary design, design development dan final design. Sehingga dihasilkan sarana bawa peralatan pembersih sepatu sneaker dengan desain yang lebih ergonomis, dan estetis yang bernuansa minimalis modern yang dilengkapi dengan meja workstation dan penyimpan peralatan pembersih sepatu sneaker dalam satu desain produk.
\end{abstract}

Kata Kunci : alat, pembawa, pembersih, sarana, sneaker 
Vol. 6, No. 2, April 2019

\section{ABSTRACT}

Shoe cleaning tools or tools generally use boxes or boxes that use wood or plastic glass materials so that they will have a long enough storage period. However, the existing shoe cleaning equipment carriers are only intended for leather shoes users. So, it has limitations for users of sneakers, canvas, nylon, suede and synthetic leather. For his own treatment, it still uses the dry cleaning method for suede shoes. But it has not yet applied the wet cleaning method for sneakers, made from canvas, nylon, and synthetic leather. Therefore, the designer plans to make a sneaker shoe cleaning equipment carrier with a shoe sneaker cleaning table with dry cleaning and wet cleaning methods. In this report entitled "Design of Facilities to Bring Equipment and Sneaker Shoe Cleaning Workstations" provides a new alternative in the design of the means to carry it, especially cleaning sneakers. The design method that is carried out is conducting preliminary design, design development and final design. So that a means to carry sneaker shoe cleaning equipment with a more ergonomic, aesthetic design with modern minimalist nuances is equipped with a workstation table and sneaker shoe cleaning equipment storage in one product design.

Keywords: tool, carrier, cleaner, means, sneaker

\section{Pendahuluan}

Peralatan atau perkakas pembersih sepatu pada umumnya menggunakan box atau kotak yang menggunakan material kayu maupun plastik kaca sehingga akan memiliki jangka waktu penyimpanan yang tidak cukup panjang. Tetapi, sarana pembawa peralatan pembersih sepatu yang ada saat ini hanya diperuntukan untuk pengguna sepatu berbahan kulit. Sehingga, memliki keterbatasan untuk pengguna sepatu sneaker yang berbahan kanvas, nylon, suede, dan kulit sintetis. Untuk perawatannya sendiri masih menggunakan metode dry cleaning untuk jenis sepatu sneaker berbahan suede. Tetapi belum menerapkan metode pembersihan wet cleaning untuk sepatu sneaker yang berbahan kanvas, nylon, dan kulit sintetis.

Sarana pembawa peralatan pembersih sepatu yaitu alat untuk membawa peralatan pembersih sepatu yang menggunakan tempat seperti box yang memiliki ruang khusus untuk tempat penyimpan peralatan pembersih sepatu. Tetapi, sarana pembawa peralatan pembersih sepatu yang ada saat ini hanya sekedar menyimpan peralatan pembersih sepatu yang belum memiliki fungsi lainnya yaitu meja alas untuk tem- pat membersihkan sepatu.

Sarana pembawa peralatan pembersih sepatu kali ini yang akan dibuat memiliki meja alas pembersih sepatu dengan metode dry cleaning dan wet cleaning sehingga untuk pengguna sepatu sneaker yang berbahan kanvas, nylon, dan kulit sintetis bisa menggunakan sarana pembawa peralatan pembersih sepatu ini dengan metode wet cleaning dan untuk pengguna sepatu sneaker berbahan suede bisa menggunakan metode dry cleaning.

\section{Metode Perancangan}

Beberapa tahapan desain menurut Goel(1995), pelaksanaan yang harus dilakukan secara terus menerus adalah:

\section{Preliminary Design}

Pengumpulan data dari informasi analisis data berdasarkan konsep desain makro yang meliputi analisis konsep (konsep fungsi, konsep pemakaian, pemakaian pasar dan konsep produk), penyusunan program desain sketsa awal. Bagian di atas terdiri dari: Perumusan Masalah, Tinjauan Pustaka, Analisis 


\section{Design Development}

Pada tahap ini dibuat alternatif gambar komponen serta rancangan secara wire diagram dengan bentuk sketsa dan 3D (tiga dimensi) dari bagian yang tertera di atas terdiri dari beberapa Desain Alternatif.

\section{Final Design \& Prototype}

Dibuat gambar-gambar yaitu dengan presentasi 3D dan gambar teknik (gambar-gambar tampak, potongan, gambar detail dan spesifikasi teknik produk) tahapan selanjutnya adalah pembuatan komponen-komponen dilakukan assembling (exploded) atau perakitan sehingga menjadi produk (prototype).

\section{Pembahasan}

\subsection{Studi Aktivitas dan Kebutuhan}

Berdasarkan hasil-hasil pengamatan terhadap proses membersihkan sepatu sneaker di tempat jasa pencucian sepatu sneaker, ada beberapa tahap dalam proses membersihkan sepatu sneaker dengan 2 metode yaitu wet cleaning dan dry cleaning.

Setelah diketahui proses aktivitas dalam membersihkan sepatu dengan metode wet cleaning dan dry cleaning. Maka didapatkan peralatan-peralatan yang dibutuhkan pengguna pada saat proses aktivitas membersihkan sepatu sneaker. Analisis aktivitas dan kebutuhan dilakukan untuk mengetahui aktivitas-aktivitas yang dilakukan berkaitan dengan produk yang akan dibuat sehingga diperoleh daftar kebutuhan pengguna.

Dari analisis aktivitas dan kebutuhan, maka telah didapatkan kesimpulan mengenai komponen-komponen apa saja yang harus ada dalam produk. Komponen-komponen tersebut antara lain:

- Tempat untuk meletakkan sikat pembersih debu.

- Tempat untuk meletakkan mangkuk air.

- Tempat untuk meletakkan sabun cair pembersih sepatu sneaker dan parfum sepatu sneaker.
- Tempat untuk meletakkan sikat standard brush dan premium brush.

- Tempat untuk meletakkan handuk microfiber.

- Tempat untuk meletakkan foam pembersih sepatu sneaker.

- Tempat untuk meletakkan wipe pembersih sepatu sneaker.

- Tempat meja alas pembersih sepatu sneaker.

Setelah didapatkan komponen-komponen yang akan diaplikasikan, maka akan dikelompokkan beberapa sekat atau ruang sesuai kebutuhan peralatan pembersih sepatu sneaker serta ukuran yang akan digunakan ke dalam produk.

\subsection{Analisis Ergonomi dan Anthropo- metri}

Analisis ergonomi dan anthropometri dibutuhkan untuk menganalisa secara detail ukuran produk yang digunakan, serta kenyamanan untuk pengguna agar hasil akhirnya dapat sesuai dengan tujuan yang diharapkan. Ergonomi sangat diperlukan dalam pembuatan produk. Begitu juga dengan produk perancangan sarana bawa peralatan dan workstation pembersih sepatu sneaker. Berikut penjelasannya:

- Berat produk harus mampu diangkat tangan pengguna berjenis kelamin pria dengan rentang usia 20 tahun hingga 35 tahun yaitu dengan bobot $8 \mathrm{~kg}$.

- Sarana bawa dan penyimpan peralatan pembersih sepatu sneaker ini memiliki wadah-wadah khusus berupa sekat yang disesuaikan dengan jenis dan berat masing-masing peralatan agar tidak berbenturan dan tidak mudah rusak.

- Produk dilengkapi dengan handle stainless sehingga akan memudahkan untuk mengangkat produk.

- Material produk terbuat dari bahan multiplek $12 \mathrm{~mm}$. Karena material multiplek adalah material yang cukup kuat untuk menampung peralatan pembersih sepatu sneaker. 
Vol. 6, No. 2, April 2019

Anthropometri yang digunakan un-

Analisis anthropometri dilakukan untuk mendapatkan dimensi atau ukuran produk yang sesuai dengan tubuh pengguna. Berdasarkan materi dari studi pustaka antrophometri sebelumnya maka dilakukan analisis anthropometri yang akan diaplikasikan pada produk agar sesuai dengan kenyamanan pengguna.

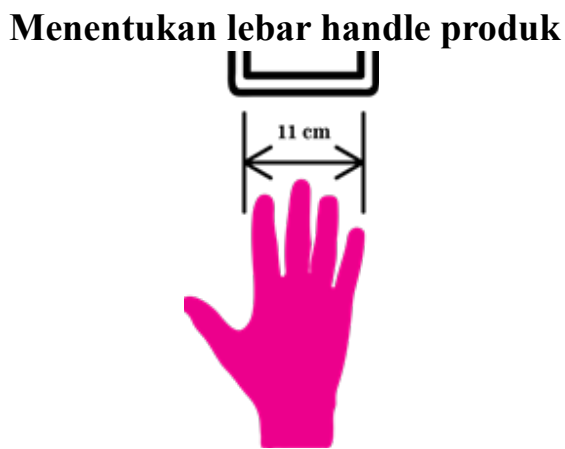

Sumber: Desain Pribadi

Gambar 1. Dimensi Lebar Genggaman Tangan

Anthropometri yang digunakan untuk menentukan lebar handle adalah lebar telapak tangan (sampai ibu jari) berjenis kelamin pria dengan kisaran umur 20 tahun hingga 30 tahun dengan ukuran $10,8 \mathrm{~cm}$ $(95 \%)$. anthropometri yang digunakan untuk menentukan lebar handle pada produk agar bisa dibawa dengan nyaman, yaitu lebar handle minimal $11 \mathrm{~cm}$.

\section{Menentukan diameter genggam handle/ gagang produk}

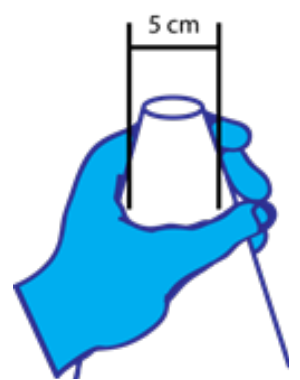

Sumber: Nurmianto, 2004

Gambar 2. Diameter Genggaman Handle/ Gagang Produk tuk menentukan diameter genggam adalah diameter genggam (maksimum) berjenis kelamin pria dengan kisaran usia 20 tahun hingga 30 tahun dengan ukuran $4,5 \mathrm{~cm}$ (5\%). Anthropometri yang digunakan untuk menentukan diameter handle/gagang pada produk agar bisa digenggam dan dibawa dengan nyaman, yaitu diameter handle/gagang maksimal $5 \mathrm{~cm}$.

\section{Menentukan ukuran alas sepatu pada produk}

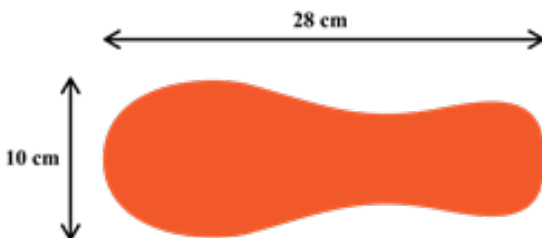

Sumber: Desain Pribadi

Gambar 3. Dimensi Lebar dan Panjang Tatakan Sepatu

Antropometri yang digunakan untuk menentukan lebar dan panjang tatakan sepatu adalah ukuran kaki. Gender laki-laki kisaran umur 20 tahun ke atas dengan ukuran $28 \mathrm{~cm}$. Anthropometri ini digunakan untuk menentukan lebar dan panjang tatakan sepatu supaya memudahkan penggunaan pada tatakan sepatu, yaitu panjang dan lebar tatakan sepatu minimal $28 \mathrm{~cm}$.

\subsection{Analisis Konfigurasi}

Analisis konfigurasi dilakukan guna mendapatkan susunan atau konfigurasi dari tiap-tiap komponen yang terdapat pada produk. Adapun komponen yang terdapat pada produk adalah:

- Tempat untuk meletakkan sikat pembersih noda suede dan suede eraser.

- Tempat untuk meletakkan mangkuk air.

- Tempat untuk meletakkan sabun cair pembersih sepatu sneaker dan parfum sepatu sneaker.

- Tempat untuk meletakkan sikat standard brush dan premium brush. 


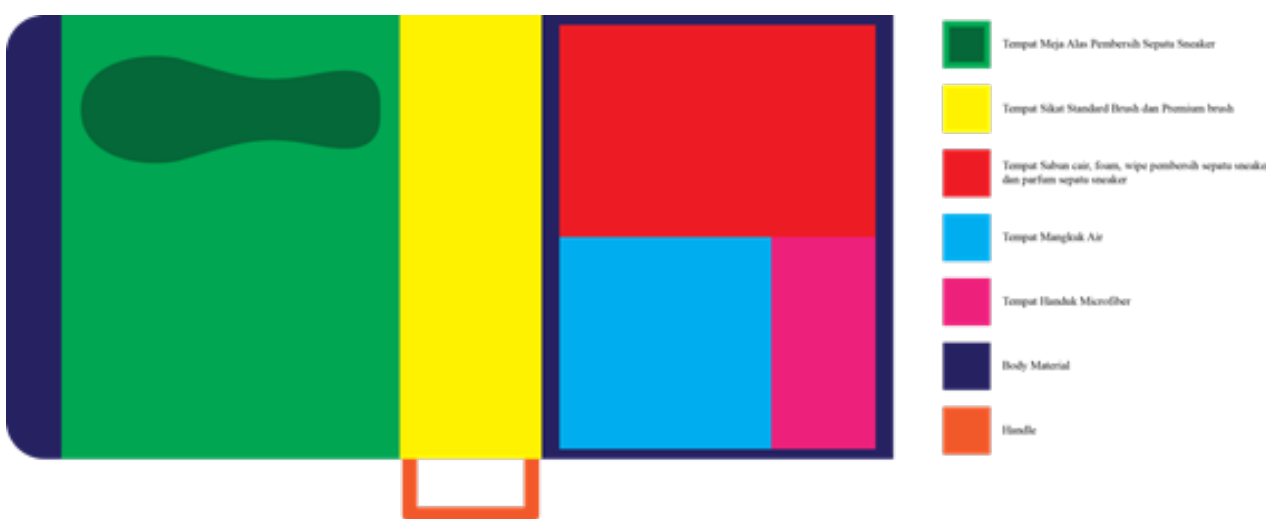

Sumber: Desain Pribadi

Gambar 4. Konfigurasi Produk

- Tempat untuk meletakkan handuk microfiber.

- Tempat untuk meletakkan foam pembersih sepatu sneaker.

- Tempat untuk meletakkan wipe pembersih sepatu sneaker.

- Tempat meja alas pembersih sepatu sneaker.

Dari komponen-komponen yang telah disebutkan, maka akan dikelompokkan dan disusun untuk mengetahui penempatan komponen yang sesuai. Berikut merupakan analisis konfigurasi tiap-tiap komponen pada sarana membawa dan penyimpanan peralatan pembersih sepatu sneaker:

Pada analisis konfigurasi dalam gambar 4, pada bagian dalam body terdapat tempat atau ruang untuk menyimpan peralatan sabun cair, foam, dan wipe pembersih sepatu sneaker serta parfum sneaker yang terletak pada bagian sisi kanan atas berwarna merah. Pada bagian tengah berwarna kuning sekat untuk sikat standard brush dan premium brush. Pada bagian kanan bawah berwarna biru untuk tempat atau ruang meletakkan mangkuk air dan warna pink untuk tempat atau ruang untuk meletakkan handuk microfiber. Warna hijau tempat meja alas pembersih sepat sneaker dan warna hijau tua tempat untuk meletakkan sepatu sneaker.

\subsection{Analisis Sistem}

Analisis sistem perlu dilakukan untuk mengetahui sistem-sistem apa saja diperlukan pada produk agar dapat berfungsi secara benar tanpa mengurangi kenyamanan produk. Berikut analisis dari sistemsistem yang digunakan pada produk.

\section{System sambungan kayu}

Dari jenis-jenis sistem sambungan kayu yang telah dianalisis, maka sistem sambungan kayu yang cocok untuk diaplikasikan pada produk ini yaitu sistem sambungan kayu miter joint.

\section{System perekat kayu}

Dari jenis-jenis sistem perekat kayu, hasil analisis yang yang cocok untuk diaplikasikan pada produk yaitu sistem perekat kayu Lem Aica Aibon untuk perekat material finishing HPL dan Lem Resin Alifatik untuk perekat sambungan kayu.

\section{Handle}

Dari hasil analisis handle yang cocok untuk diaplikasikan pada produk yaitu handle stainless.

\section{Kuncian}

Dari hasil analisis kuncian yang cocok untuk diaplikasikan pada produkyaitu kuncian pengait koper. 
Vol. 6, No. 2, April 2019

Engsel

Dari hasil analisis engsel yang cocok untuk diaplikasikan pada produk yaitu engsel kupu-kupu dan engsel sendok untuk sistem buka tutup pada produk dan engsel pegas yang digunakan sebagai sandaran pada meja alas pembersih sepatu sneaker.

\subsection{Analisis Material}

Analisis material dilakukan guna mengetahui material yang tepat untuk digunakan pada produk Adapun analisisnya sebagai berikut:

\section{Material Body dan Material Meja Alas Pembersih Sepatu}

Dalam memilih material yang digunakan untuk produk, syarat-syarat yang harus dipertimbangkan antara lain adalah material yang digunakan harus ringan saat diangkat serta kuat dalam hal anti air saat proses membersihkan sepatu sneaker dan tidak mudah rapuh saat menampung peralatan pembersih sepatu sneaker serta biaya yang cukup murah. Dari hasil analisis material yang cocok untuk diaplikasikan pada produk yaitu multiplek untuk material body dan material meja alas pembersih sepatu.

\section{Material Finishing}

Dalam memilih material finishing syarat-syarat yang harus dipertimbangkan antara lain adalah material finishing yang digunakan harus tahan lama, awet, dan memiliki warna yang bermacam-mcam yang bisa diaplikasikan ke produk sesuai konsepnya serta biaya yang cukup murah. Dari hasil analisis yang cocok untuk diaplikasikan pada produk yaitu finishing material cat duco.

\subsection{Analisis Bentuk}

Sarana membawa dan penyimpan peralatan pembersih sepatu sneaker memerlukan bentuk gaya desain yang akan diaplikasikan pada produk sebagai acuan bentuk produk yang diinginkan serta dengan mempertimbangkan target konsumen yang dituju yaitu berjenis kelamin pria dan memiliki tingkat ekonomi menengah ke atas dengan gaya hidup minimalis dan praktis serta dengan perilaku konsumen yang selalu mengikuti gaya masa kini. Dari beberapa acuan tersebut, ada beberapa bentuk gaya desain yang bisa menyesuaikan acuan studi kasus konsumen yang dapat diaplikasikan pada produk antara lain gaya desain modern minimalis dan gaya desain futuristik. Diantara bentuk gaya desain tersebut harus dipilih salah satunya melalui analisis yang mempertimbangkan aspek-aspek lainnya sebagai item penilaian yakni kemudahan pengerjaan serta kesesuaian target konsumen. Berikut analisisnya:

Dari hasil analisis terpilih bentuk gaya desain modern minimalis yang akan diaplikasikan pada produk karena memenuhi semua aspek penilaian dan serta diharapkan mampu menopang seluruh komponen produk.

\subsection{Analisis Warna}

Analisis warna dilakukan guna menentukan warna yang sesuai untuk diaplikasikan pada produk perancangan sarana bawa peralatan dan workstation pembersih sepatu sneaker. Pendekatan yang digunakan dalam analisis ini adalah hubungan warna dengan psikologi pengguna produk, Adapun warna-warna dominan yang berpotensi digunakan adalah warna netral. Warna netral tersebut adalah warna hitam, putih, cream, abu-abu, dan coklat tua. Dari 5 warna netral yang telah disebutkan maka terpilih warna hitam dan coklat tua. Dikarenakan produk ini berhubungan dengan proses pembersihan sepatu sneaker maka diperlukan warna yang tidak mudah kotor pada saat proses pembersihan sepatu sneaker yaitu warna hitam dan warna coklat tua. Produk ini ditargetkan oleh kalangan kaum pria dengan rentang usia 20 - 35 tahun maka warna hitam dan coklat tua lebih cocok untuk diaplikasikan pada produk sarana bawa peralatan dan workstation pembersih sepatu sneaker. 


\subsection{Hasil Desain}

Desain akhir adalah gambaran terakhir produk yang telah tercapai setelah melewati proses desain. Dimulai dari desain awal, pengembangan desain, sampai desain terpilih. Dimana desain akhir tersebut terbagi dalam beberapa gambar detail, antara lain adalah gambar final, gambar presentasi, gambar teknik, dan foto prototype. Berikut adalah desain akhir produk Desain Sarana Bawa Peralatan dan Workstation Pembersih Sepatu Sneaker.

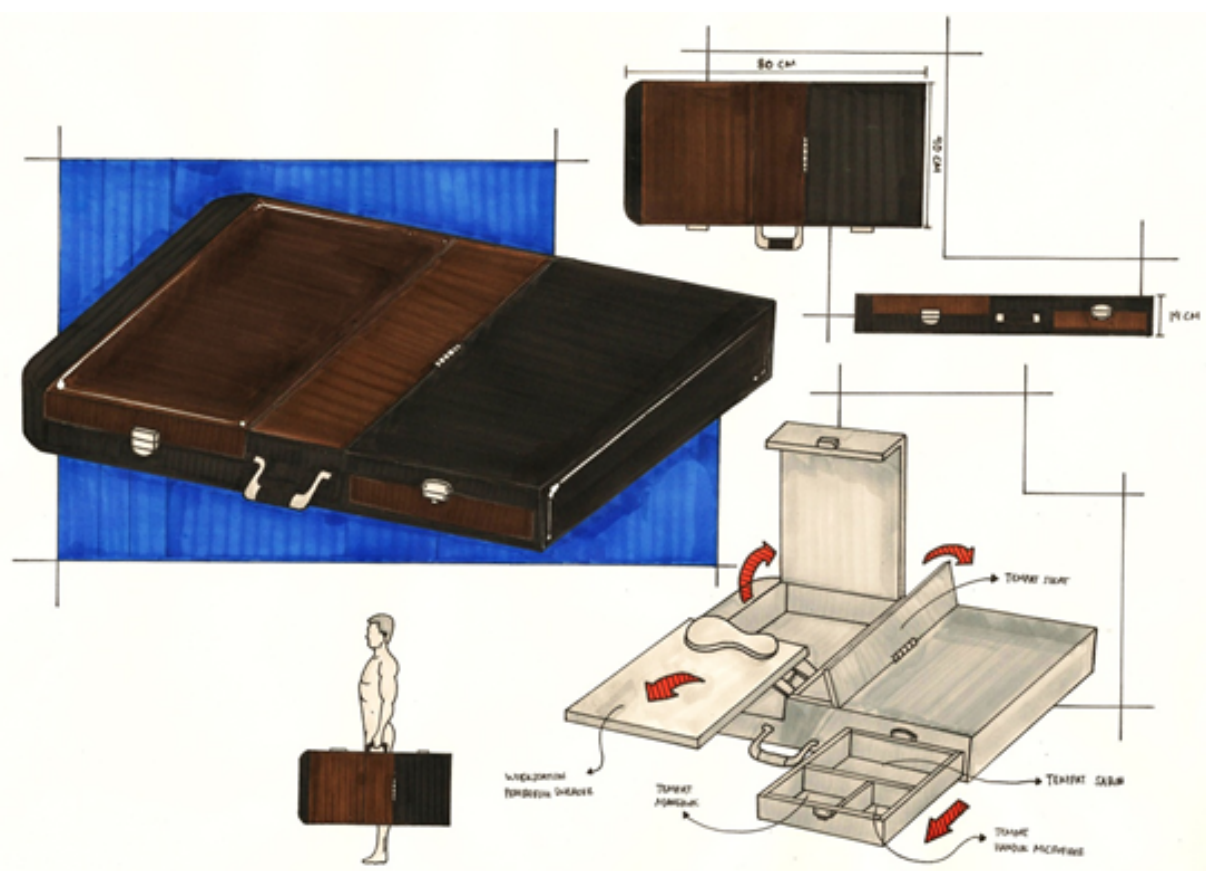

Sumber: Desain Pribadi

Gambar 5. Gambar Final

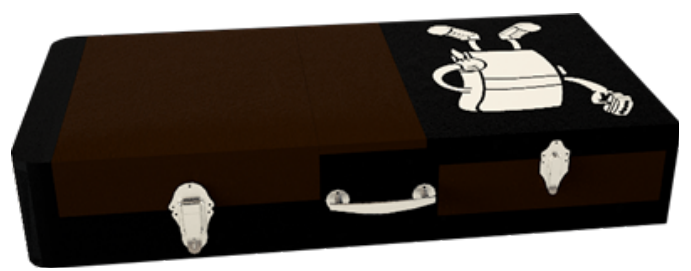

Sumber: Desain Pribadi

Gambar 6. Gambar Presentasi

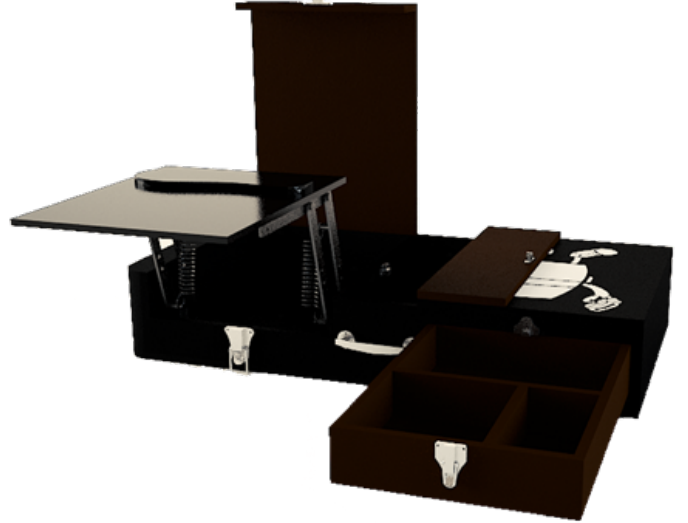

Sumber: Desain Pribadi Gambar 7. Gambar Presentasi 
Vol. 6, No. 2, April 2019

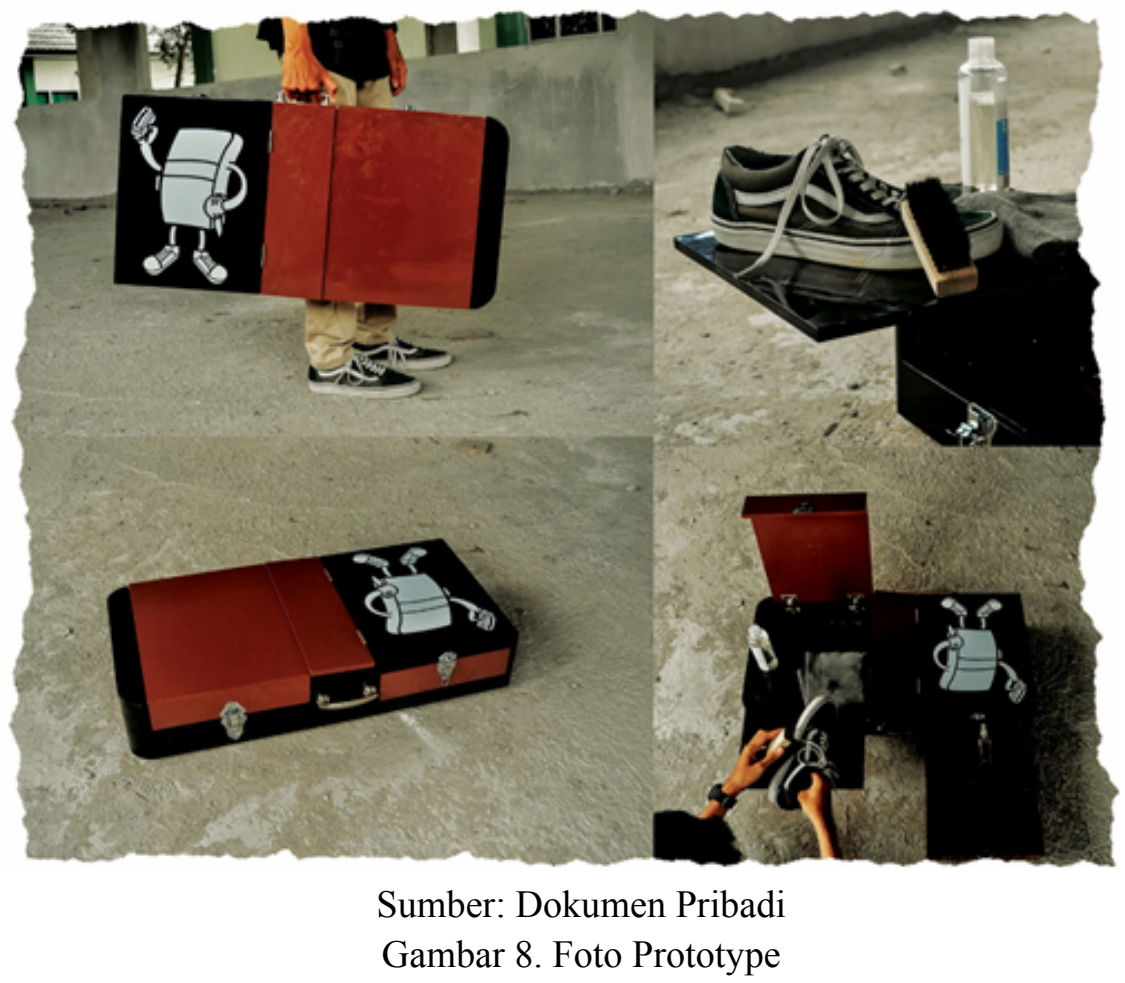

\section{KESIMPULAN}

Kesimpulan dari hasil perancangan "Desain Sarana Bawa Peralatan dan Workstation Pembersih Sepatu Sneaker" ialah sebagai berikut:

Sarana membawa dan penyimpanan ini dapat menampung sabun pembersih sepatu sneaker, foam pembersih sepaatu sneaker, wipe pembersih sepatu sneaker, dan parfum sepatu sneaker.

Sarana membawa dan penyimpanan ini memiliki tempat workstation yang digunakan untuk tempat atau area pembersih sepatu sneaker.

Sarana membawa dan penyimpan ini menggunakan warna hitam sebagai warna utama dan warna coklat tua sebagai warna aksentuasi agar bisa memadukan dengan warna hitam.

Saran yang dapat saya berikan adalah sarana membawa dan penyimpanan peralatan pembersih sepatu sneaker ini masih dapat dikembangkan menjadi lebih, baik dari sistem dari segi buka tutup, kuncian, handle serta workstation pembersih sepatu, bentuk yang minimalis maupun warna produk yang cocok digunakan untuk kalangan kaum pria yang digunakan untuk menyelesaikan produk ini. Pembuatan sarana membawa dan penyimpanan peralatan pembersih sepatu sneaker ini diharapkan kedepannya dapat mengembangkan produk ini lebih baik lagi dari yang sebelumnya. 


\section{DAFTAR RUJUKAN}

Nurmianto, Eko. (2008). Ergonomi: Konsep Dasar dan Aplikasinya, Edisi Pertama. Guna Widya. Surabaya. Indonesia.

Fashionary. (2015). Shoe Design a Handbook for Footwear Designers.

Suharbianto. (2018). Desain Sarana Bawa Alat Perkebunan. Tugas Akhir. Politeknik Negeri Samarinda. Samarinda. Indonesia.

Alfari. (2017). Mengenal Triplek atau Kayu Lapis. https://www.arsitag.com/article/mengenal-triplek-atau-kayu-lapis. Diakses pada 6 Maret 2019.

Kania. (2018). Beda Jenis Engsel Pintu, Beda Fungsinya: Ini yang Harus Kamu Tahu. https://www.dekoruma.com/artikel/70588/jenis-engsel-pintu. Diakses pada 6 Maret 2019.

Luqman, Hilmy. (2014). Sejarah Sneakers dan Perkembangannya di Indonesia. http:// hilmyluqmanap.blogspot.com/2014/05/sejarah-sneakers-dan perkembangannya-di.html. Diakses pada 6 Maret 2019. 